\title{
La política sobre arrendamiento urbano en el Perú contemporáneo
}

Sección ESTUDIOS

RECIBIDO: $15 / 10 / 2020$

APROBADO: $23 / 11 / 2020$

PUBLICADO ONLINE: 18/12/2020

\author{
JohnnyZas Friz Burga \\ Pontificia Universidad Católica del Perú \\ jzasfris@pucp.edu.pe \\ https://orcid.org/0000-0003-4523-7872
}

\section{RESUMEN}

El artículo analiza la política sobre arrendamiento urbano en el Perú contemporáneo y busca explicar el origen y la permanencia del intervencionismo contractual en materia de arrendamiento urbano hasta el siglo XXI. Son analizados todos los periodos políticos, desde los gobiernos de Augusto Leguía (1919-1930) hasta los gobiernos de la última transición democrática (2000-2020) y se busca mostrar muy sintéticamente las múltiples determinaciones del intervencionismo contractual. El análisis de la política pública sobre arrendamiento urbano se desarrolla en el marco del proceso contemporáneo de urbanización peruano, definido por el desarrollo de la llamada barriada como la forma a través de la cual los sectores populares urbanos accedieron a la vivienda a partir de la década del cincuenta del siglo XX y de cómo se incorporaron y se integraron a la ciudad; y el paralelo debilitamiento de la identificación entre tugurio, arrendamiento y vivienda de los sectores populares urbanos.

PALABRAS CLAVE: políticas públicas; arrendamiento urbano; intervencionismo contractual; gobiernos peruanos; historia urbana; procesos de urbanización; vivienda; acceso a la vivienda popular.

\section{Policy on urban leasing in contemporary Peru}

\section{ABSTRACT}

The article analyzes the urban leasing policy in contemporary Peru and seeks to explain the origin and permanence of contractual interventionism in urban leasing until the 21 st century. All political periods are analyzed, from the governments of Augusto Leguía (1919-1930) to the governments of the last democratic transition (2000-2020) and it seeks to show very synthetically the multiple determinations of contractual interventionism. The analysis of public policy on urban leasing is developed within the framework of the contemporary Peruvian urbanization process, defined by the development of the so-called neighborhood as the way through which the urban popular sectors accessed housing from the decade from the fifties of the 20th century and how they were incorporated and integrated into the city; and the parallel weakening of the identification between slum, rental and housing of the urban popular sectors.

KEYWORDS: Public Policies; Urban Leasing; Contractual Interventionism; Peruvian Governments; Urban History; Urbanization Processes; Housing; Access to Popular Housing. 


\section{Introducción conceptual y metodológica}

$\mathrm{E}$ objetivo de este artículo es presentar y explicar la política sobre arrendamiento urbano en el Perú contemporáneo, desde el año 1920, año en el cual se dicta la primera ley que inicia el intervencionismo contractual en materia de arrendamiento urbano en el Perú, hasta la actualidad.

La propuesta metodológica asume una perspectiva interdisciplinaria e integral como condición para analizar la historicidad y la racionalidad de los procesos jurídicos que dieron contenido al intervencionismo público en materia de arrendamiento urbano.

El derecho como formalización de la política pública se estudia como una realidad concreta que integra en su análisis a las ciencias sociales. Este enfoque determina que el análisis jurídico esté acompañado con análisis político, económico y sociológico.

El análisis busca aproximarse a las múltiples determinaciones que constituyen las normas jurídicas y las políticas públicas, así como a las realidades que el derecho y la política determinan o condicionan.

Este trabajo muestra y analiza la producción legislativa sobre arrendamiento urbano en el proceso social del Perú desde el año 1920 hasta la actualidad.

Metodológicamente, este artículo se divide por periodos de gobierno. Esta división es pertinente para identificar la especificidad de cada uno de los gobiernos nacionales - o conjuntos de gobiernos nacionales - desde el año 1920 hasta hoy.

Una de las hipótesis planteadas es que un ordenamiento jurídico civil absolutamente libre fue incapaz de regular la relación arrendatario-propietario, desde el proceso de urbanización de inicios del siglo XX, específicamente, desde la década del veinte del siglo XX.

La legislación intervencionista limitó, en determinado universo de contratos de arrendamiento, la autonomía de la voluntad y el derecho de propiedad, sustentando esta intervención en un discurso de transitoriedad y de excepcionalidad. Sin embargo, esta regulación se volvió permanente: la intervención contractual siempre volvió en los pocos momentos de regulación absolutamente libre del contrato de arrendamiento urbano.

La intervención en la relación contractual arrendatario-propietario permitió la existencia misma de esta relación social y el derecho y la política pública hicieron posible el acceso a la vivienda de amplios sectores sociales de la ciudad.

El artículo busca mostrar al derecho como el mecanismo de mediación de las decisiones de política pública frente a problemas sociales generados por el desarro- 
llo histórico de nuestro país, en este caso, la urbanización creciente y el problema del arrendamiento urbano.

También se presentan los cambios producidos por la irrupción de la llamada barriada o barrio marginal a través de la "invasión" y de la creación de la "ciudad informal". Este proceso aminoró la gravedad del conflicto en la relación arrendatariopropietario en los sectores populares urbanos, y generó la identificación entre el arrendamiento y la vivienda tugurizada de las áreas centrales de nuestras ciudades.

El artículo analiza la producción legislativa y la implementación de las políticas públicas en materia de arrendamiento urbano en el marco del desarrollo de la vivienda urbana y de la constitución de la ciudad como aglomeración espacial dentro de un proceso social e histórico, asociados de manera indesligable a la barriada, al tugurio y a la vivienda alquilada.

\section{Los gobiernos de Augusto Leguía (1919-1930) ${ }^{1}$}

En el siglo veinte, en la década del diez, la relación arrendatario-propietario aparece como un problema social y ello genera un contexto favorable para sustraer esta relación jurídica de la regulación del Código Civil, estableciéndose una regulación especial del arrendamiento de predios urbanos.

La relación arrendatario-propietario se convierte en un problema social porque los montos de arredramientos aumentan y la creciente población arrendataria en las ciudades, fundamentalmente sectores populares, no puede pagar tales montos de arrendamiento por tener bajos ingresos.

En los años referidos, los ingresos de los trabajadores asalariados solo permitían pagar los montos de arrendamiento de viviendas tugurizadas, es decir, de cuartos alquilados con malas condiciones de habitabilidad.

La problemática generada por el aumento de los montos de arrendamiento de las viviendas tugurizadas que albergaban a los sectores populares de las ciudades hizo que la rebaja de los alquileres se convirtiera en una reivindicación del movimiento obrero de la época.

1 Para este periodo político consultar: Yepes Del Castillo, Ernesto. (1981). Perú 1820-1920. Un Siglo de Desarrollo Capitalista. Lima, Perú: Ediciones Signo; Cotler, Julio. (1978). Clases, Estado y Nación en el Perú. Lima, Perú: IEP; Sulmont, Denis. (1980). El Movimiento Obrero Peruano (1890-1980). Reseña Histórica. Lima, Perú:TAREA; Flores Galindo, Alberto y Burga, Manuel. (1981). Apogeo y Crisis de la República Aristocrática. Lima, Perú: Rikchay Perú; Basadre, Jorge. (1963). Historia de la República del Perú. Lima, Perú: Editorial Universitaria; Quijano, Aníbal. (1985). Imperialismo, Clases Sociales y Estado en el Perú 1890-1930. Lima, Perú: Mosca Azul Editores; Caravedo, Baltazar. (1977). Clases, Lucha, Política y Gobierno en el Perú (1919-1933). Lima, Perú: Retama Editorial; Stein, Steve. (1986). Lima Obrera 1900-1930. Tomo I. Lima, Perú: Ediciones El Virrey; y Matos Mar, José. (1977). Las Barriadas de Lima 1957. Lima, Perú: IEP. 
La política de expansión de la ciudad de Lima, promovida especialmente por el régimen de Augusto Leguía, generó una gran especulación con el suelo y la vivienda urbanas, y ello tuvo efectos directos en el alza de los alquileres en la ciudad.

Paralelamente, el intervencionismo contractual que tuvo la política de alquileres seguida por el régimen político del Presidente Augusto Leguía produjo la aminoración del impacto de la especulación urbana — generada también por la misma política estatal expansiva de la ciudad - en los alquileres.

La política urbana del régimen del Presidente Augusto Leguía permitió una gran especulación urbana, especialmente en Lima, pero sustrajo del libre mercado al universo de contratos de alquiler de las mayorías urbanas populares, disminuyendo así la presencia de los alquileres en el gasto de los presupuestos populares y medios.

La legislación dictada en materia de arrendamiento urbano durante todo este periodo, desde un enfoque jurídico, implicó legislar para grupos sociales y ya no para individuos considerados en abstracto y como portadores solo de intereses particulares.

El Estado intervino en la regulación libre de la relación arrendatario-propietario para atender un problema social concreto y objetivo: los sectores populares y medios solo podían acceder a la vivienda alquilada si se intervenía la determinación libre del contenido de los contratos de arrendamiento. Toda la legislación dictada en materia de arrendamiento urbano fue aprobada y presentada como transitoria. Sin embargo, esta transitoriedad fue permanente en todo el periodo político analizado.

Hubo un discurso jurídico ideológico —en un sentido negativo- que insistió en la transitoriedad de esta intervención contractual que sustraía a determinados contratos de arrendamiento de una regulación libre en el mercado. Sin embargo, la permanencia de esta legislación evidenciaba que había una realidad social concreta que interpelaba la regulación libre de los alquileres si se quería permitir el acceso a la vivienda de los sectores populares y medios.

\section{La crisis del treinta y el gobierno de Luis Sánchez Cerro (1930-1933) ${ }^{2}$}

La crisis del treinta agravó aún más el ya existente problema de los alquileres.

Por esta crisis, la disminución de los ingresos de los asalariados y el desempleo hicieron que los arrendatarios no pudieran pagar los montos de arrendamiento y

2 Para este periodo político consultar: Cotler, Julio (1982). "La crisis política 1930-1968". En: Lumbreras, Luis Guillermo. Nueva Historia General del Perú. Lima: Mosca Azul Editores; Caravedo Molinari, Baltazar (1979). "Poder central y descentralización: Perú 1931". APUNTES, Revista de Ciencias Sociales de la Universidad del Pacífico, Lima, Año V, Número 9; Borea Odría, Alberto (1980). ¿Qué ha hecho el APRA por el Perú? Lima: Imprenta Editora Atlántida; Cotler, Julio (1978). Clases, Estado y nación en el Perú. Lima: IEP; Quijano, Aníbal (1985). Imperialismo, Clases sociales y Estado en el Perú 1890-1930. Lima: Mosca Azul Editores; y Caravedo Molinari, Baltazar (1977). Clases, lucha política y gobierno en el Perú (1919-1933). Lima: Retama Editorial. 
ello provocó la participación del Estado. El Gobierno del periodo prorrogó las leyes de prohibición de aumento de alquileres y dispuso la suspensión de la interposición de acciones de desahucio.

Durante el régimen político del Presidente Augusto Leguía, así como durante la Junta Militar de Gobierno que lo derrocó, la relación ingresos-empleo-alquileres era fundamental para sustentar la intervención contractual en los contratos de arrendamiento de predios urbanos.

El desempleo y la no percepción de ingresos por parte de los sectores populares y medios eran el argumento de la intervención del Estado en el mercado y en la regulación libre del contrato de arrendamiento para prohibir el aumento de los alquileres y para suspender las acciones de desahucio.

Con su famoso "Plan Mínimo", el APRA introdujo como relación principal para determinar el monto del arrendamiento la relación entre el valor del predio y el alquiler.

Esta fue una novedosa introducción conceptual en la década del treinta y si bien no olvidaba los ingresos de los arrendatarios en el alquiler -ya que la imposibilidad de pagar sustentaba siempre la intervención en el contrato de arrendamientodaba más importancia al valor del predio en la determinación del alquiler que a los ingresos de los arrendatarios.

A fines del mes de febrero del año 1931, en tres zonas distintas del país, se instalaron gobiernos autónomos que desconocían a Luis Sánchez Cerro. Se formó una Junta de Gobierno en Arequipa que legisló paralelamente a la Junta de Gobierno de Lima durante casi un mes; y entre las medidas dictadas por esta Junta de Gobierno estaba la rebaja de alquileres de habitaciones y casas.

Esta exigencia de rebaja de alquileres en Arequipa mostraba la vinculación directa existente entre el proceso de urbanización, la especulación con el suelo y la vivienda urbanos, y el aumento de los alquileres. También mostraba que los trabajadores obreros mantenían como reivindicación la rebaja de los alquileres, en tanto la vivienda alquilada los albergaba.

Durante todo este periodo, continuaba la ilusión de la transitoriedad del intervencionismo contractual. La excepcionalidad planteada en el discurso jurídico y político era cuestionada en los hechos: la exigencia de la permanencia de la intervención se sustentaba en la necesidad de acceder a la vivienda alquilada por los sectores populares y medios.

Una regulación libre del mercado de la vivienda arrendada impedía el acceso de los sectores populares a esta vivienda alquilada, constituida por cuartos con malas condiciones de habitabilidad. 


\section{El Gobierno de Óscar Benavides (1933-1939)}

En el gobierno de Óscar Benavides se instaura una política social del Estado que pretende satisfacer ciertas demandas de los sectores populares urbanos.

En materia de vivienda, los principales signos de esta política social son: la creación de la Inspección de la Vivienda Obrera como primera instancia estatal especializada y la construcción de viviendas populares.

La creación de esta Inspección de la Vivienda Obrera hacía manifiesta la existencia de las malas condiciones de habitabilidad del tugurio alquilado, que era la clase de vivienda que albergaba a los obreros; y la necesidad de enfrentar esta problemática.

En el año 1933, las Leyes Nㅜ 6074 y № 6778 dejaron de regir ya que las prórrogas a estas leyes terminaron. De tal manera que, a partir del año 1934, se inicia un primer momento de libre mercado en la regulación de los alquileres desde el año 1920. Esta regulación por el libre mercado de los contratos de arrendamiento de predios urbanos generó un alto aumento de los alquileres, aumento que afectó gravemente a los presupuestos de las familias no solo obreras sino también medias.

La especulación con los alquileres determinó que el Gobierno de Óscar Benavides dictara la Ley $N^{\circ} 8766$ en el año 1938, para evitar esta alta especulación que no permitía el acceso a la vivienda alquilada de las mayorías urbanas. El libre mercado en la regulación de la relación arrendatario-propietario generaba altos alquileres que no podían ser pagados por los — potenciales o ya — arrendatarios.

Con esta Ley $N^{\circ} 8766$ se da la primera argumentación jurídica distinta a la tradicional. Por primera vez, se hizo explícita la consideración de la vivienda como subsistencia.

Asimismo, se argumentó que el alquiler era la relación contractual que permitía el acceso a la vivienda, y que este contrato de arrendamiento debía regularse para poder satisfacer la necesidad de vivienda de los sectores populares y medios. Esta Ley $N^{\circ} 8766$, limitó el monto del arrendamiento y restringió las causales de desahucio y de aviso de despedida.

En este periodo se dicta una nueva Constitución Política y un nuevo Código Civil.

Tanto la Constitución Política del año 1933, así como el Código Civil del año 1936, sustentaban la validez jurídica de la Ley $N^{\circ} 8766$. Sin embargo, la argumentación

3 Para este periodo político consultar: Portocarrero Maisch, Gonzalo. (1983). De Bustamante a Odría. El Fracaso del Frente Democrático Nacional 1945-1950. Lima, Perú: Mosca Azul Editores; Cotler, Julio. (1978). Clases, Estado y Nación en el Perú. Lima, Perú: IEP; Caravedo Molinari, Baltazar. (1977). Clases, Lucha, Política y Gobierno en el Perú (1919-1933). Lima, Perú: Retama Editorial; y Sulmont, Denis. (1980). El Movimiento Obrero Peruano (1890-1980). Reseña Histórica. Lima, Perú: TAREA. 
a favor de la citada norma, continuaba planteando que la Ley $N^{\circ} 8766$ - y todas las leyes con un contenido similar - correspondían a una legislación transitoria y excepcional.

\section{El primer Gobierno de Manuel Prado (1939-1945)}

En este periodo de gobierno, se hace más evidente un proceso de desintegración de la sociedad agraria peruana, el cual provocó una mayor urbanización del país.

En un contexto de mayor urbanización, se produjo una mayor demanda de viviendas, y una mayor especulación con el suelo y la vivienda urbanas. Por ello, la legislación del periodo, en materia de arrendamiento urbano, que inicialmente solo prohibía el aumento de alquileres en Lima y Callao, se amplió.

En el primer gobierno del Presidente Manuel Prado, la legislación intervencionista en materia de arrendamiento urbano pasó a regir en todo el territorio nacional. Antes de esta ampliación general para todo el país, se legisló — primero- para todo el departamento de Lima y — segundo- para Arequipa.

En este periodo, la vivienda fundamental de los sectores populares seguía siendo el cuarto alquilado. En el año 1940, los cuartos alquilados tugurizados eran las viviendas mayoritarias en las principales ciudades del país.

En el año 1940, los salarios aumentaban solo más que los alquileres de cuartos. Sin embargo, los obreros gastaban la mayoría de su ingreso en alimentos y dada la baja capacidad adquisitiva de sus ingresos, solo podían alquilar cuartos si los montos de arrendamiento eran regulados ya que una determinación del monto del alquiler en una regulación por el libre mercado no habría permitido alquilar.

La Ley N 8766 rigió —a través de varias prórrogas — durante todo el primer gobierno del Presidente Manuel Prado.

Las prórrogas de la citada Ley se hicieron para permitir que los montos de alquiler no significaran altos porcentajes en los presupuestos de los hogares de

4 Para este periodo político consultar: Portocarrero Maisch, Gonzalo. (1983). De Bustamante a Odría. El Fracaso del Frente Democrático Nacional 1945-1950. Lima, Perú: Mosca Azul Editores; Wendorff, Carlos. (1983). Población, Urbanización y Vivienda en el Perú. En: Aramburú López de Romaña, Carlos Eduardo. Población y Política de Desarrollo en el Perú. Lima, Perú: INANDEP; Riofrío, Gustavo. (1978). Se Busca Terreno Para Próxima Barriada. Espacios Disponibles de Lima 1940-1978-1990. Lima, Perú: DESCO; Golte, Jürgen y Adams, Norma. (1987). Los Caballos de Troya de los Invasores. Estrategias Campesinas en la Conquista de la Gran Lima. Lima, Perú: IEP; Deler, Jean Paul. (1975). Aspectos del Crecimiento de la Capital Peruana. Lima 1940-1970. Lima, Perú: Centro de Investigaciones Geográficas; Caravedo Molinari, Baltazar. (1977). Clases, Lucha, Política y Gobierno en el Perú (1919-1933). Lima, Perú: Retama Editorial; DESCO. (1970). Análisis de los Avisos de Oferta de Vivienda y Terrenos en Lima Metropolitana 1940-1967. Lima, Perú: DESCO; Sánchez León, Abelardo y Otros. (1986). Tugurización en Lima Metropolitana. Lima, Perú: DESCO; y Cotler, Julio. (1978). Clases, Estado y Nación en el Perú. Lima, Perú: IEP. 
los sectores populares urbanos. El pago de altos alquileres habría significado la imposibilidad de satisfacer otras necesidades, tales como la alimentación, por parte de los sectores populares urbanos.

\section{El Frente Democrático Nacional y el Gobierno de José Luis Bustamante y Rivero (1945-1948)}

En este periodo se evidencia el déficit estructural de viviendas en las ciudades. Hay una manifiesta mayor demanda de viviendas en las ciudades asociadas a un conjunto de causas estructurales de la sociedad peruana de la época y una muy reducida oferta de viviendas frente a su amplísima demanda en las ciudades de todo el país.

Hay un contexto en el cual la mayoría de la población urbana que quiere acceder a una vivienda tiene bajos ingresos y su demanda de vivienda presiona al alza la especulación con los alquileres, también favorecida por los propietarios de los predios urbanos.

El problema de la escasez de vivienda ofrecida por el mercado existente expresaba una crisis irreversible - por lo menos - en el corto plazo, crisis en la cual los alquileres en una regulación de libre mercado no permitían a las mayorías urbanas acceder a una vivienda, incluso al cuarto tugurizado con malas condiciones de habitabilidad.

En este periodo se evidencia el problema estructural de la vivienda y la imposibilidad de dar una solución a la cuestión de la habitación popular de la nueva población de las ciudades por los medios convencionales, incluyendo el tradicional alquiler de las viviendas tugurizadas.

En el devenir histórico de nuestras ciudades, en este periodo- en esta década y en la siguiente década de los años cincuenta del siglo XX — los tugurios clásicos darán el lugar a las barriadas como la forma de acceder a la vivienda por parte de los sectores pobres de las ciudades.

5 Para este periodo político consultar: Cotler, Julio. (1978). Clases, Estado y Nación en el Perú. Lima, Perú: IEP; Portocarrero Maisch, Gonzalo. (1983). De Bustamante a Odría. El Fracaso del Frente Democrático Nacional 1945-1950. Lima, Perú: Mosca Azul Editores; Borea Odría, Alberto. (1980). ¿Qué Ha Hecho el APRA por el Perú? Lima, Perú: Imprenta Editora Atlántida; Sulmont, Denis. (1980). El Movimiento Obrero Peruano (1890-1980). Reseña Histórica. Lima, Perú:TAREA; Deler, Jean Paul. (1975). Aspectos del Crecimiento de la Capital Peruana. Lima 1940-1970. Lima, Perú: Centro de Investigaciones Geográficas; Collier, David. (1978). Barriadas y Élites: De Odría a Velasco. Lima, Perú: IEP; Matos Mar, José. (1977). Las Barriadas de Lima 1957. Lima, Perú: IEP; y DESCO. (1970). Análisis de los Avisos de Oferta de Vivienda y Terrenos en Lima Metropolitana 1940-1967. Lima, Perú: DESCO. 
Los nuevos alquileres no podían ser pagados por los potenciales arrendatarios y así aparecía la barriada como un modelo alternativo de ocupación del espacio urbano, ante la segregación producida por los nuevos alquileres.

La inflación fue otro factor que nutrió la especulación con los alquileres. Parte de esta especulación consistía en la búsqueda, de parte de los propietarios, de desocupar las viviendas que tenían antiguos contratos de alquiler para volver a alquilarlas con nuevos montos de arrendamiento más elevados.

Este proceso inflacionario determinó que el Gobierno Nacional dictara el reglamento - y su ampliatoria- de la Ley $\mathrm{N}^{\circ} 10222$ y normas complementarias ante un grave problema de desocupación de arrendatarios por el afán de lucro de los propietarios.

El proceso inflacionario producido en la época generó, por un lado, un mayor afán de lucro en los propietarios y, por otro, la imposibilidad de pagar los nuevos alquileres por los arrendatarios.

El cuarto alquilado tugurizado como vivienda de los sectores populares urbanos se mantuvo y convivió con la barriada.

Hubo aún una identidad entre el alquiler y la vivienda tugurizada de los sectores populares urbanos. En este contexto, el Departamento de Inspección de Inquilinato siguió siendo un órgano estatal relevante.

\section{El Gobierno de Manuel Odría (1948-1956)}

El gobierno del Presidente Manuel Odría fue un régimen de explícita ideología económica liberal, pero mantuvo una legislación intervencionista en materia de alquileres.

Nuevamente, se evidenciaba que una regulación libre del mercado de los alquileres para los sectores populares urbanos, así como la total discrecionalidad del propietario para hacer desocupar los predios arrendados a los arrendatarios de bajos ingresos, habría provocado un objetivo y grave problema social en las ciudades.

6 Para este periodo político consultar: Portocarrero Maisch, Gonzalo. (1983). De Bustamante a Odría. El Fracaso del Frente Democrático Nacional 1945-1950. Lima, Perú: Mosca Azul Editores; Deler, Jean Paul. (1975). Aspectos del Crecimiento de la Capital Peruana. Lima 1940-1970. Lima, Perú: Centro de Investigaciones Geográficas; Collier, David. (1978). Barriadas y Élites: De Odría a Velasco. Lima, Perú: IEP; Matos Mar, José. (1977). Las Barriadas de Lima 1957. Lima, Perú: IEP; Wendorff, Carlos. (1983). Población, Urbanización y Vivienda en el Perú. En: Aramburú López de Romaña, Carlos Eduardo. Población y Política de Desarrollo en el Perú. Lima, Perú: INANDEP; Cotler, Julio. (1978). Clases, Estado y Nación en el Perú. Lima, Perú: IEP; Pinzás, Teobaldo. (1981). La Economía Peruana 1950-1978. Ensayo Bibliográfico. Lima, Perú: IEP; Sánchez León, Abelardo y Otros. (1986). Tugurización en Lima Metropolitana. Lima, Perú: DESCO; y Cotler, Julio. (1982). La Crisis Política 1930-1968. En: Lumbreras, Luis Guillermo. Nueva Historia General del Perú. Lima, Perú: Mosca Azul Editores. 
Esta consideración social hizo que el gobierno del Presidente Manuel Odría mantuviera el intervencionismo contractual en la legislación sobre arrendamiento urbano del periodo. Al igual que otros regímenes políticos de ideología económica liberal, el gobierno de Manuel Odría no derogó las leyes de alquileres.

En los primeros años del régimen político del Presidente Manuel Odría, hubo una inflación que aunada al déficit estructural del mercado de la vivienda para los sectores populares y medios produjo una muy alta especulación con los alquileres.

Un efecto importante de la inflación de la época fue la significativa distancia entre los montos de los nuevos alquileres y los montos de los antiguos alquileres. Esta diferencia entre nuevos y antiguos alquileres se acentuó y llevó a que los propietarios buscaran la desocupación de sus predios arrendados.

Otro fenómeno social importante en este periodo fue la importancia que tuvo el subarrendamiento. Ello indicaba que se estaba frente a una transición en la composición de los arrendatarios, ya que el subarrendamiento implicaba la no necesidad de la vivienda subalquilada para el arrendatario.

En este periodo los sectores populares comienzan a ser reemplazados por el crecimiento de los sectores medios como arrendatarios. Ya en la década de los cincuenta del siglo XX, la barriada comienza a ser la forma de acceso preeminente a la vivienda para los sectores sociales pobres de la ciudad.

En este periodo también destacó la política de excepciones de determinados inmuebles a la legislación sobre alquileres. El propósito fue promover una actividad lucrativa en determinados inmuebles arrendados para favorecer a determinadas instituciones. Antes, solo estaban exceptuadas de la legislación sobre arrendamiento urbano las Sociedades de Beneficencia Pública.

\section{El Segundo Gobierno de Manuel Prado (1956-1962)}

Al inicio de este periodo, en el año 1956, los ingresos de las mayorías urbanas no permitían a éstas alquilar en una regulación determinada por el libre mercado.

En este periodo, el no poder pagar alquileres por los sectores populares de la ciudad era una causa importante para la invasión y la subsiguiente generación de la barriada.

$7 \quad$ Para este periodo político consultar: Córdova Valdivia, Adolfo. (1958). La Vivienda en el Perú. Estado Actual y Evaluación de las Necesidades. Lima, Perú: Comisión para la Reforma Agraria y la Vivienda; Matos Mar, José. (1977). Las Barriadas de Lima 1957. Lima, Perú: IEP; Sánchez León, Abelardo y Otros. (1986). Tugurización en Lima Metropolitana. Lima, Perú: DESCO; Wendorff, Carlos. (1983). Población, Urbanización y Vivienda en el Perú. En: Aramburú López de Romaña, Carlos Eduardo. Población y Política de Desarrollo en el Perú. Lima, Perú: INANDEP; Deler, Jean Paul. (1975). Aspectos del Crecimiento de la Capital Peruana. Lima 1940-1970. 
Casi al final del periodo, en el año 1961, los ingresos de las mayorías urbanas estaban en peores condiciones que hacía cinco años: solo una tercera parte de empleados y un reducido número de obreros y de trabajadores independientes podían alquilar a precios de libre mercado.

De otro lado, los sectores sociales que podían alquilar casas o departamentos, preferían comprarlos - especialmente casas - a través del financiamiento brindado por las instituciones del sistema financiero de la época.

Entre los años 1950 y 1960, los sueldos y los salarios solo aumentaron más que los alquileres de cuartos. Hipotéticamente el cuarto era la única clase de vivienda que podía alquilarse por parte de los sectores populares de la ciudad.

En este periodo se produce una significativa disminución de la vivienda alquilada por el desarrollo de la barriada. La vivienda alquilada en el año 1961 disminuyó respecto del año 1940, de representar el 84.9\% pasó a ser el $69.1 \%$ del total de viviendas.

En el año 1960 también se hace visible otro hecho concreto que confirma el decaimiento de la vivienda alquilada: disminuyeron los avisos de cuartos para alquilar.

Los cuartos alquilados dejaron de ser la principal forma de habitación para los sectores populares urbanos como lo habían sido en las décadas de 1940 y de 1950.

En este periodo, el tugurio dio paso a la barriada como principal forma de acceso a la vivienda y a la ciudad; y los tugurios comenzaron a identificarse solo con las áreas más tradicionales y centrales de las ciudades.

Los profundos cambios sociales ocurridos en el país produjeron una importante discusión en materia de vivienda promovida por la Comisión de Vivienda y Reforma Agraria. Este debate generó cambios en la política sobre las barriadas y la vivienda en el país.

También hubo una discusión ideológica muy importante en la que se enfrentaron las tesis del libre mercado planteadas por Pedro Beltrán y las tesis de Adolfo Córdova que consideraba a la vivienda como parte del problema social del Perú. En

Lima, Perú: Centro de Investigaciones Geográficas; Collier, David. (1978). Barriadas y Élites: De Odría a Velasco. Lima, Perú: IEP; Riofrío, Gustavo. (1978). Se Busca Terreno Para Próxima Barriada. Espacios Disponibles de Lima 1940-1978-1990. Lima, Perú: DESCO;Webb, Richard. (1975). Políticas Gubernamentales y Distribución del Ingreso en el Perú: 1961-1971. En: Figueroa, Adolfo y Richard Webb. Distribución del Ingreso en el Perú. Lima, Perú: IEP; Sulmont, Denis. (1980). El Movimiento Obrero Peruano (18901980). Reseña Histórica. Lima, Perú: TAREA; Harris, Walter D. y Hosse, Hans A. (1963). La Vivienda en el Perú. Housing in Perú. Washigton D. C., Estados Unidos de América: Unión Panamericana, Secretaría General OEA; Golte, Jürgen y Adams, Norma. (1987). Los Caballos de Troya de los Invasores. Estrategias Campesinas en la Conquista de la Gran Lima. Lima, Perú: IEP; DESCO. (1970). Análisis de los Avisos de Oferta de Vivienda y Terrenos en Lima Metropolitana 1940-1967. Lima, Perú: DESCO; y Cotler, Julio. (1978). Clases, Estado y Nación en el Perú. Lima, Perú: IEP. 
materia de alquileres, la tesis de Pedro Beltrán no fue aceptada y se mantuvieron las leyes de alquileres.

La Ley de Barriadas, Ley $\mathrm{N}^{\circ} 13517^{8}$, convirtió a los arrendatarios en propietarios y prohibió la interposición de las acciones de desahucio y de aviso de despedida en las barriadas. Estas medidas tuvieron el propósito de sustraer del libre mercado a la vivienda de la barriada, para evitar así la especulación con ella a través de los altos alquileres.

Un efecto muy importante generado por la citada Ley se produjo con relación a las barriadas internas. La posibilidad y el hecho concreto de querer acogerse a la Ley $N^{\circ} 13517$ de parte de estos tugurios internos - en las áreas centrales de la ciudad - mostró la precariedad e inseguridad que tenían sus arrendatarios. Por ello, buscaron incorporarse en el ámbito de la denominada Ley de Barriadas.

\section{La Junta Militar de Gobierno de 1962-1963}

En este periodo, la legislación dictada por la junta militar de gobierno siguió y profundizó los lineamientos de la Ley $\mathrm{N}^{\circ}$ 13517. La legislación dictada amplió el universo de juicios con sentencia que podían suspenderse, al establecer que podían incluirse en la Ley $N^{\circ} 13517$ a todos aquellos juicios con sentencias anteriores a la fecha estipulada inicialmente por la referida Ley $\mathrm{N}^{\circ} 13517$.

De esta manera, la legislación dictada por la junta militar de gobierno evitó el desalojo de los arrendatarios de tugurios que habían dejado de pagar alquileres para lograr ingresar en el ámbito de la Ley $\mathrm{N}^{\circ} 13517$, declarando moratoria de alquileres entre otras medidas.

Desde una perspectiva más general, la junta militar de gobierno intentó sentar las bases de algunas reformas sociales. Destacaron las disposiciones sobre reforma agraria y sobre la resolución de los problemas presentados por la aplicación de la Ley $N^{\circ} 13517$ en materia de alquileres en las áreas centrales de la ciudad.

\section{El primer Gobierno de Fernando Belaunde (1963-1968) ${ }^{9}$}

En este periodo concluye el proceso conflictivo iniciado con la aplicación de la Ley № 13517: se prohibió el inicio de juicios de desahucio, interdictos y toda acción civil seguida contra cualquier ocupante ubicado en barrio marginal.

8 Ley que declara de necesidad y utilidad públicas e interés nacional la remodelación, saneamiento y legalización de los barrios marginales o barriadas, existentes en las áreas urbanas y suburbanas del territorio nacional.

9 Para este periodo político consultar: Cotler, Julio. (1978). Clases, Estado y Nación en el Perú. Lima, Perú: IEP Collier, David. (1978). Barriadas y Élites: De Odría a Velasco. Lima, Perú: IEP; Riofrío, Gustavo. (1978). 
En este periodo político, se cierra el proceso de sustracción de una regulación libre del mercado de la vivienda a todas las viviendas existentes en las denominadas barriadas.

Nuevamente, se evidenció la disminución de la importancia relativa de los alquileres. La composición del ingreso nacional de la época mostró que los alquileres disminuyeron frente a las utilidades empresariales $y$ a los sueldos $y$ salarios.

Los propietarios de los predios ya arrendados no cobraban los montos de arrendamiento que una regulación libre del mercado les hubiera permitido por la presencia de las leyes de alquileres

Hubo una cierta redistribución en favor de los arrendatarios. El monto de alquiler no cobrado por el propietario - es decir, la diferencia entre el monto cobrado y el monto mayor que hipotéticamente se podría haber cobrado en una regulación libre de mercado - se quedaba como ingreso del arrendatario. Sin embargo, esta redistribución se produjo solo en los denominados antiguos alquileres.

La mayoría de las familias que vivían en la ciudad no podían pagar nuevos alquileres: los sueldos y salarios solo aumentaron más que los alquileres de cuartos; y la composición del ingreso nacional demostraba que los salarios habían disminuido. Por lo tanto, la mayoría de asalariados iban hacia la barriada en su búsqueda de vivienda, ante la imposibilidad de pagar nuevos alquileres.

En este periodo, se produjo un cambio en la política de excepciones a la legislación sobre alquileres.

En materia de política de excepciones a la legislación sobre alquileres, anteriormente, se favoreció al Estado y a otras instituciones, fundamentalmente, asistenciales y religiosas.

En este periodo, se constituyó un nuevo universo de contratos de arrendamiento alternativo a los "antiguos alquileres", que se reguló por el libre mercado y que estaba exceptuado de la legislación sobre alquileres.

Se Busca Terreno Para Próxima Barriada. Espacios Disponibles de Lima 1940-1978-1990. Lima, Perú: DESCO; Sánchez León, Abelardo y Otros. (1986). Tugurización en Lima Metropolitana. Lima, Perú: DESCO; Webb, Richard. (1975). Políticas Gubernamentales y Distribución del Ingreso en el Perú: 1961-1971. En: Figueroa, Adolfo y Richard Webb. Distribución del Ingreso en el Perú. Lima, Perú: IEP; Sulmont, Denis. (1980). El Movimiento Obrero Peruano (1890-1980). Reseña Histórica. Lima, Perú: TAREA; Kuczynski, Pedro Pablo. (1980). Democracia Bajo Presión Económica. El Primer Gobierno de Belaúnde. Lima, Perú: Ediciones Treintaitres y Mosca Azul Editores; DESCO. (1970). Análisis de los Avisos de Oferta de Vivienda y Terrenos en Lima Metropolitana 1940-1967. Lima, Perú: DESCO; Deler, Jean Paul. (1975). Aspectos del Crecimiento de la Capital Peruana. Lima 1940-1970. Lima, Perú: Centro de Investigaciones Geográficas; Cotler, Julio. (1975). Crisis Política y Populismo Militar. En: Fuenzalida, Fernando. Perú: Hoy. México, México: Siglo XXI Editores; y De Althaus Guarderas, Miguel. (1971). Derecho Administrativo. Materiales de Enseñanza. Lima, Perú: Pontificia Universidad Católica del Perú. 


\section{El Gobierno de Juan Velasco Alvarado (1968-1975) ${ }^{10}$}

En este periodo, siguió evidenciándose la pérdida de importancia relativa de los alquileres.

En el año 1972, la vivienda alquilada siguió disminuyendo y ya más de la mitad del total de las viviendas eran propias.

Para los sectores populares urbanos, la barriada ya se había constituido en la vivienda alternativa al cuarto de alquiler tugurizado y lo había desplazado en importancia.

En el año 1972, los distritos con más pueblos jóvenes —la nueva denominación de las antiguas barriadas - tenían los mayores porcentajes de obreros y de trabajadores independientes. En este periodo, se evidenciaba que la vivienda alquilada correspondía a los sectores medios, empobrecidos o no.

Durante los primeros años del período, la población de los pueblos jóvenes y del estrato de bajos ingresos — en Lima — gastaba más de la mitad de su ingreso en bebidas y alimentos. $Y$ en estos mismos sectores, se presentaban los más bajos gastos en vivienda: $17.39 \%$ en los pueblos jóvenes y $15.34 \%$ en el sector bajo.

Asimismo, las familias que vivían en casa alquilada tenían en promedio un gasto menor que las familias que vivían en casa propia.

En los pueblos jóvenes la vivienda era propia; en el estrato de bajos ingresos de la población era en donde se hallaban los arrendatarios; y el promedio bajo en gasto de vivienda se debía a la presencia de antiguos alquileres.

10 Para este periodo político consultar: Cotler, Julio. (1975). Crisis Política y Populismo Militar. En: Fuenzalida, Fernando. Perú: Hoy. México, México: Siglo XXI Editores; Pease, Henry. (1980). El Ocaso del Poder Oligárquico. Lima, Perú: DESCO; Wendorff, Carlos. (1983). Población, Urbanización y Vivienda en el Perú. En: Aramburú López de Romaña, Carlos Eduardo. Población y Política de Desarrollo en el Perú. Lima, Perú: INANDEP; Sánchez León, Abelardo y Otros. (1986). Tugurización en Lima Metropolitana. Lima, Perú: DESCO; Riofrío, Gustavo. (1978). Se Busca Terreno Para Próxima Barriada. Espacios Disponibles de Lima 1940-1978-1990. Lima, Perú: DESCO; Golte, Jürgen y Adams, Norma. (1987). Los Caballos de Troya de los Invasores. Estrategias Campesinas en la Conquista de la Gran Lima. Lima, Perú: IEP; Henry, Etienne. (1978). La Escena Urbana. Estado y Movimientos de Pobladores 1968-1976. Lima, Perú: Pontificia Universidad Católica del Perú; Sánchez León, Abelardo y Calderón Cockburn, Julio. (1987). El Laberinto de la Ciudad. Políticas Urbanas del Estado 19501979. Lima, Perú: DESCO; Figueroa, Adolfo. (1974). Estructura del Consumo y Distribución de Ingresos en Lima Metropolitana. 1968-1969. Lima, Perú: CISEPA, Departamento de Economía de la Pontificia Universidad Católica del Perú; Velasco Alvarado, Juan. (s.f.). La Voz de la Revolución. Discursos. Lima, Perú: PEISA; Collier, David. (1978). Barriadas y Élites: De Odría a Velasco. Lima, Perú: IEP; Cleaves, Peter y Pease, Henry. (1985). Autonomía Estatal y Decisión Política Militar. En: Lowenthal, Abraham y Cynthia Mc Clintock. El Gobierno Militar. Una Experiencia Peruana 1968-1980. Lima, Perú: IEP; Mc Clintock, Cynthia. (1985). Velasco, Funcionarios y Ciudadanos: Políticas de Cautela. En: Lowenthal, Abraham y Cynthia Mc Clintock. El Gobierno Militar. Una Experiencia Peruana 1968-1980. Lima, Perú: IEP; Pinzás, Teobaldo. (1981). La Economía Peruana 1950-1978. Ensayo Bibliográfico. Lima, Perú: IEP; Sulmont, Denis. (1980). El Movimiento Obrero Peruano (1890-1980). Reseña Histórica. Lima, Perú: TAREA; y Ramos Padilla, Miguel y Frías Coronado, Carlos. (1980). La Vivienda: Un Derecho Violado en el Perú. Lima, Perú: CIDAP. 
Nuevamente, como en periodos anteriores, se mostraba una cierta redistribución del ingreso entre los propietarios arrendadores y los arrendatarios de antiguos alquileres; $y$ que la barriada generaba al poblador un menor gasto en vivienda.

Para la junta militar de gobierno dirigida por Juan Velasco, los objetivos principales de la política urbana eran los pueblos jóvenes, las áreas tugurizadas y la especulación urbana con los terrenos.

Para la citada junta militar de gobierno, la vivienda alquilada no resolvería el déficit de viviendas y el enfrentamiento del problema de los alquileres no era prioritario, Ello se evidenció cuando al inicio del periodo, la denominada reforma urbana fue desestimada.

En un momento posterior, la propuesta de reforma urbana nuevamente apareció y tenía como propósito enfrentar la especulación con los alquileres realizada por los grandes propietarios o inmobiliarias, a través de la regulación de los montos de arrendamiento y de un mecanismo original para promover la construcción de viviendas alquiladas.

Las marchas, contramarchas y contradicciones presentes en el periodo en torno a la denominada reforma urbana expresaron la lucha política al interior del régimen e impidieron que esta reforma urbana se concretara.

Durante este periodo la regulación de los alquileres fue libre. La junta militar de gobierno no derogó la norma dictada en el gobierno anterior que exceptuaba de las leyes de alquileres a todos los contratos de arrendamiento celebrados con posterioridad al mes de agosto del año 1968.

Esta regulación de los nuevos contratos de arrendamiento por el Código Civil duró hasta el mes de junio del año 1975, fecha en la cual se restringió la procedencia de los juicios de aviso de despedida y de desahucio.

Esta restricción se produjo porque los propietarios invocaban causales distintas de la necesidad de ocupar la única casa habitación para desalojar a sus antiguos arrendatarios y después cobrar nuevos alquileres en un periodo inflacionario importante.

Este fue un segundo momento de regulación libre de los nuevos alquileres desde el año 1920.

Esta experiencia demostró - nuevamente- que una regulación libre de los alquileres, en un mercado de la vivienda determinado por su déficit estructural, generaba una mayor especulación con los alquileres y que para evitarla había que intervenir en el mercado de los alquileres. Un contexto semejante se había producido durante los primeros años del gobierno del Presidente Óscar Benavides, en la década del treinta del siglo XX. 
En el año 1973, los salarios solo aumentaron más que los alquileres de cuartos y los sueldos habían aumentado menos que todos los alquileres. Ya en el año 1976, todos los alquileres aumentaron más que los sueldos y los salarios. La crisis económica y la inflación generaron, nuevamente, una mayor especulación con los alquileres.

Durante este periodo, hasta antes de la crisis económica, se produjeron las mayores cantidades de obras privadas en vivienda, en los años 1972, 1973, 1974 y 1975; y paralelamente la participación de los alquileres en el Producto Bruto Interno (PBI) disminuyó en el mismo periodo.

En este periodo existió una determinación libre de los nuevos contratos de arrendamiento de predios urbanos y una importante expansión de la actividad constructora, sin embargo, no hubo una específica inversión en vivienda para arrendamiento entre los años 1968 y 1975.

La inversión de la industria de la construcción se produjo en la vivienda unifamiliar para la venta porque resultaba una actividad más rentable que la explotación de predios con nuevos alquileres. Esta experiencia demostró que una regulación libre del alquiler no significó una mayor inversión en vivienda para arrendamiento.

\section{El Gobierno de Francisco Morales Bermúdez (1975-1980) ${ }^{11}$}

La junta militar de gobierno planteó el establecimiento de normas legales que regularan los alquileres.

11 Para este periodo político consultar: Cleaves, Peter y Pease, Henry. (1985). Autonomía Estatal y Decisión Política Militar. En: Lowenthal, Abraham y Cynthia Mc Clintock. El Gobierno Militar. Una Experiencia Peruana 1968-1980. Lima, Perú: IEP; Riofrío, Gustavo. (1978). Se Busca Terreno Para Próxima Barriada. Espacios Disponibles de Lima 1940-1978-1990. Lima, Perú: DESCO; Wendorff, Carlos. (1983). Población, Urbanización y Vivienda en el Perú. En: Aramburú López de Romaña, Carlos Eduardo. Población y Política de Desarrollo en el Perú. Lima, Perú: INANDEP; Sánchez León, Abelardo y Calderón Cockburn, Julio. (1987). El Laberinto de la Ciudad. Políticas Urbanas del Estado 1950-1979. Lima, Perú: DESCO; Henry, Etienne. (1978). La Escena Urbana. Estado y Movimientos de Pobladores 1968-1976. Lima, Perú: Pontificia Universidad Católica del Perú; Pinzás, Teobaldo. (1981). La Economía Peruana 1950-1978. Ensayo Bibliográfico. Lima, Perú: IEP; Sulmont, Denis. (1980). El Movimiento Obrero Peruano (1890-1980). Reseña Histórica. Lima, Perú: TAREA; Figallo, Guillermo y Polack, César. (s.f.). Ley de Alquileres. Decreto Ley 21938 y su Reglamentación. Lima, Perú: Imprenta Editora Atlántida S. A.; De La Puente y Lavalle, Manuel. (1983). Estudios del Contrato Privado. Lima, Perú: Cultural Cuzco S. A. Editores; De Trazegnies, Fernando. (1978). La Transformación del Derecho de Propiedad. DERECHO. Programa Académico de Derecho de la PUCP. Número 33. Lima, Fondo Editorial de la Pontificia Universidad Católica del Perú; Sánchez León, Abelardo y Otros. (1986). Tugurización en Lima Metropolitana. Lima, Perú: DESCO; Avendaño Valdez, Jorge. (1984). Atributos y Caracteres del Derecho de Propiedad. En: Cárdenas Quiros, Carlos. Para Leer el Código Civil. Vol. Il. Lima, Perú: Fondo Editorial de la Pontificia Universidad Católica del Perú; Espinoza Brinkmain, Pedro. (1978). Crecimiento y Distribución. La Ley de Alquileres: Decreto Ley 21938. (Tesis de Bachiller). Pontificia Universidad Católica del Perú, Lima; Ramos Padilla, Miguel y Frías Coronado, Carlos. (1980). La Vivienda: Un Derecho Violado en el Perú. Lima, Perú: CIDAP; y Grados, Rómulo y Otros. (1980). La Pobreza de Lima Metropolitana. Socialismo y Participación. Lima, CEDEP, Número 11. 
El gobierno del periodo no hizo ninguna mención a una reforma urbana ni señaló cuál sería el criterio de la regulación de alquileres; pero, sí planteó, en materia de vivienda y construcción, que debían mejorarse significativamente las condiciones de vivienda de la población y promoverse la inversión pública y privada en la construcción.

Sin embargo, en el año 1976, la gravedad de la crisis económica y social era evidente y la caída del salario y del sueldo reales era también muy importante.

En este mismo año de 1976, se dictó una legislación que buscó una mayor inversión en vivienda, así como resolver el problema de los alquileres hasta la dación de una ley de inquilinato.

La política en materia de alquileres del primer año del gobierno de la junta militar dirigida por Francisco Morales Bermúdez terminó con la regulación libre de los nuevos alquileres, aunque ya en el año 1975 se habían restringido las causales del desahucio y del aviso de despedida, así como su tramitación.

Al inicio del periodo, se suspendió el aumento de los alquileres en las casas habitación, se restringieron las causales de las acciones de desocupación en los centros educativos particulares y se pretendió fomentar la inversión en viviendas de tipo económico para alquiler.

En este periodo de gobierno, en el mes de setiembre del año 1977, se dicta la norma más importante en materia de arrendamiento urbano por varias décadas: el Decreto Ley Nº 21938.

El diagnóstico y el objetivo del Decreto Ley $N^{\circ} 21938$ fueron la existencia de inseguridad y de inestabilidad en la relación jurídica entre propietario y arrendatario; la posibilidad de una relación armónica entre propietario y arrendatario; y la búsqueda de evitar la especulación con los alquileres a través del establecimiento de una función social de la propiedad y de la intervención de los contratos.

El Decreto Ley $N^{\circ} 21938$ fue la primera norma que pretendió regular en forma definitiva la relación arrendatario-propietario. Desde el año de 1945, se había planteado la dación de una ley definitiva de inquilinato.

El diagnóstico de este Decreto Ley se sustentó en la grave crisis económica de la época. Esta crisis produjo, en una regulación estrictamente civil de libre mercado, montos de arrendamiento muy altos y acciones de desocupación más numerosas.

Este contexto de crisis había llevado a la junta militar de gobierno de Francisco Morales Bermúdez a dictar la prohibición del aumento del monto de arrendamiento en el año 1976; y a la junta militar de gobierno de Juan Velasco Alvarado a restringir y suspender las acciones de desahucio y de aviso de despedida en el año 1975. 
Con la crisis, nuevamente, la especulación con los nuevos alquileres recrudecía y debía atacarse un problema que afectaba directamente el ingreso familiar de los sectores populares y medios.

El Decreto Ley № 21938 recogió mucho de la legislación dictada en los casi sesenta años anteriores a su dación; e incluyó la relación entre el monto del alquiler y el valor del predio, una propuesta del Plan Mínimo del APRA en el año 1931 y también del Plan Inca del Gobierno de Juan Velasco Alvarado del año 1974.

La concreción de una relación armónica entre arrendadores y arrendatarios no fue posible, por las imprevisiones del mismo Decreto ley № 21938.

La aplicación de este Decreto Ley, en sus efectos, no amparó ni a arrendatarios ni tampoco a arrendadores, sino a algunos grupos de ambos universos.

El Decreto Ley № 21938 tuvo dos características principales: mantuvo las relaciones mercantiles fuera de los predios urbanos con fines de vivienda de cierto valor de autoavalúo, teniendo un ámbito restringido y móvil de aplicación; y limitó la autonomía de la voluntad y el ejercicio del derecho de propiedad del arrendador sin cuestionar el contenido esencial del ordenamiento jurídico civil.

\section{El Segundo Gobierno de Fernando Belaúnde (1980-1985) ${ }^{12}$}

El Perú en la década de los ochenta del siglo XX ya era un país mayoritariamente urbano. En 1981, el 65\% de la población del país estaba en las ciudades y el otro

12 Para este periodo político consultar: Wendorff, Carlos. (1983). Población, Urbanización y Vivienda en el Perú. En: Aramburú López de Romaña, Carlos Eduardo. Población y Política de Desarrollo en el Perú. Lima, Perú: INANDEP; Strassman, Paul. (1984). Empleo y Vivienda en Lima, Perú. Lima, Perú: Ministerio de Trabajo y Promoción Social, Dirección General de Empleo; Riofrío, Gustavo y Driant, Jean Claude. (1987). ¿Qué Vivienda Han Construido? Nuevos Problemas en Viejas Barriadas. Lima, Perú: CIDAP-TAREA; Matos Mar, José. (1985). Desborde Popular y Crisis del Estado. Lima, Perú: IEP; Henríquez, Narda y Ponce, Victoria. (1985). Lima: Población y Política. En: Henríquez, Narda y Victoria Ponce. Lima: Población, Trabajo y Política. Lima, Perú: Pontificia Universidad Católica del Perú; Riofrío, Gustavo. Barriada y Ciudad: Crisis de Crecimiento y Crisis Actual. En: Ortiz de Zevallos, Augusto. Lima a los 450 Años. Lima, Perú: Centro de Investigación de la Universidad del Pacífico (CIUP); García, José María. Pobreza, (1985). Población y Vivienda en Distritos de Lima Metropolitana. 1981. En: Henríquez, Narda y Victoria Ponce. Lima: Población, Trabajo y Política. Lima, Perú: Pontificia Universidad Católica del Perú; Figallo, Guillermo. (1985). Política y Derecho Agrario. Lima, Perú: Editores Impresores; Morante, Karin. (1985). Hacia una Nueva Concepción del Arrendamiento Urbano en el Perú. (Tesis de Bachiller). Pontificia Universidad Católica del Perú, Lima; Revoredo De Debakey, Delia. (1985). Código Civil. Lima, Perú: Pontificia Universidad Católica del Perú; Muñiz Z., Jorge. (1985). Arrendamiento. En: Revoredo De Debakey, Delia. Exposición de Motivos y Comentarios. TomoVI. Código Civil. Lima, Perú: Pontificia Universidad Católica del Perú; Arias Schreiber, Max. (1980). Disposiciones Generales de los Contratos. En: Pontificia Universidad Católica del Perú. Proyectos y Anteproyectos de la Reforma del Código Civil. Tomo II. Lima, Perú: Fondo Editorial de la Pontificia Universidad Católica del Perú; Avendaño Valdez, Jorge. (1984). Atributos y Caracteres del Derecho de Propiedad. En: Cárdenas Quiros, Carlos. Para Leer el Código Civil. Vol. II. Lima, Perú: Fondo Editorial de la Pontificia Universidad Católica del Perú; e Instituto Libertad y Democracia (ILD). (16 de Diciembre de 1985). De Puerta en Puerta. Informe sobre Alquileres. Revista CARETAS. 
35\% estaba en el campo, una proporción igual pero inversa a la de los años cuarenta del siglo XX.

En el año 1981, el proceso de decrecimiento de las viviendas alquiladas y de los hogares presentes en tales viviendas persistía, fundamentalmente, por el crecimiento barrial: todos los ocupantes de lotes en barriadas eran considerados propietarios.

En este periodo también se evidenciaba la continuación de la denominada penuria de la vivienda: aproximadamente un $70 \%$ de las viviendas tenían tres cuartos en el área de Lima y Callao, una situación semejante a la existente hacía cuarenta años antes.

La existencia de antiguos contratos de arrendamiento explicaba la presencia de bajos alquileres; y casi la totalidad de tugurios eran alquilados, la principal forma de acceder a la vivienda hacía cuarenta o treinta años.

Sin embargo, los nuevos alquileres fueron mayoritarios durante el segundo gobierno de Fernando Belaúnde. Los montos de estos nuevos contratos de arrendamiento aumentaban, ya que al ser contratos recién celebrados no ingresaban al ámbito del Decreto Ley $N^{\circ} 21938$.

En el periodo también se evidenció el deterioro de la vivienda alquilada y que la disminución del alquiler iba en paralelo a un aumento del valor de la vivienda. Esta situación se producía en los predios objeto de los antiguos alquileres incluidos en el Decreto Ley Nº 21938.

En la década del ochenta del siglo XX la denominada barriada se consolidó y fue el patrón de urbanización de los sectores de más bajos ingresos de la ciudad; y hubo una correspondencia entre los distritos más pobres de Lima, por ejemplo, y una menor presencia de viviendas alquiladas.

También en este periodo, se registraron valores bajos de inversión privada en viviendas los años 1982, 1983, 1984 y 1985; no obstante, durante este periodo se mantuvo una política de libre mercado en la determinación de los alquileres respecto de todos los nuevos contratos de arrendamiento celebrados.

Durante el segundo gobierno del Presidente Fernando Belaúnde, el problema de los alquileres se agravó porque debido a las imprevisiones del Decreto Ley $\mathrm{N}^{\circ}$ 21938, los nuevos contratos de arrendamiento de predios urbanos no ingresaban a su ámbito de aplicación. Tal situación generó montos de arrendamiento y de garantía muy altos y en moneda extranjera.

Durante este periodo la única disposición importante dictada fue la puesta en vigencia nuevamente de la excepción de las Sociedades de Beneficencia de las leyes sobre alquileres. 
Esta ausencia de legislación propició una regulación civil de libre mercado en materia de arrendamiento de predios urbanos para aquellos contratos excluidos del ámbito del Decreto Ley $N^{\circ} 21938$. Esta política de alquileres determinó en los contratos de arrendamiento de predios destinados a otros usos, la interposición masiva de juicios de desahucio y de aviso de despedida al igual que la fijación de brevísimos plazos para los nuevos arrendatarios. No se derogó el Decreto Ley $\mathrm{N}^{\circ}$ 21938 pero se incentivó la disminución de su ámbito de aplicación.

En este periodo, en el año 1984, se promulgó el nuevo Código Civil. Esta norma en materia de arrendamiento significó una reformulación de todo este contrato.

Un importante planteamiento de este nuevo Código Civil fue el reconocimiento de las limitaciones del mismo ordenamiento civil.

Este Código Civil reconoce que la lógica y los presupuestos del ordenamiento civil de libre mercado no tienen validez universal en todas las relaciones contractuales posibles.

El actual Código Civil reconoce la autonomía del derecho laboral, del derecho agrario y también del derecho urbano. El artículo 1712 del Código Civil dice: "los contratos de arrendamiento regulados por leyes especiales se rigen supletoriamente por las normas de este título".

Este artículo 1712 del Código Civil al declararse supletorio en materia de arrendamiento define la autonomía de esta institución jurídica respecto del ordenamiento jurídico civil general.

\section{El primer Gobierno de Alan García (1985-1990)}

Desde el mes de agosto del año 1985, se dispuso la prohibición del aumento de alquileres.

Nuevamente, se buscó enfrentar el problema del alza de los nuevos alquileres, presente en aquellos contratos excluidos del ámbito del Decreto Ley N²1938, los cuales eran los contratos mayoritarios.

En las propuestas gubernamentales del primer gobierno del Presidente Alan García se mantuvo un propósito interventor: prórroga de los contratos de arrendamiento de predios urbanos; prohibición del aumento de montos de arrendamiento y, luego, su aumento progresivo; y suspensión de las acciones de aviso de despedida y de desahucio, entre las características principales.

En general, las disposiciones normativas dictadas en este periodo fueron semejantes respecto de la legislación promovida por el APRA durante el Frente Democrático Nacional en el periodo de 1945-1948. 
También se mantuvo una paralela política de excepciones a la legislación sobre alquileres. Se exceptuaron los predios arrendados de las Sociedades de Beneficencia Pública y de otras instituciones públicas.

La legislación dictada en este periodo evidenció la ausencia de una propuesta integral respecto del arrendamiento urbano.

\section{Los gobiernos de Alberto Fujimori (1990-2000) ${ }^{13}$}

En los inicios de este periodo político, se mantuvo la prórroga de la vigencia de los contratos de arrendamiento de predios urbanos.

El Gobierno del Presidente Alberto Fujimori prorrogó hasta el mes de diciembre del año 1990 la vigencia de los contratos de arrendamiento de casa-habitación a plazo determinado y bajo el ámbito de cualquier régimen legal.

El nuevo periodo político se caracterizó por iniciar un proceso de liberalización de precios. Esta liberalización se implementó a través del Decreto Supremo Nㅜ 22690-EF, del mes de agosto del año 1990, el cual estableció que a partir de esa fecha "Ios precios de los bienes y servicios se fijarán de acuerdo al comportamiento de la oferta y la demanda". Sin embargo, esta misma norma exceptuó de esta liberalización a los contratos de arrendamiento de casas-habitación.

Con el Decreto Supremo № 301-90-EF, del mes de noviembre del año 1990, se inició la liberalización de los contratos de arrendamiento de predios urbanos.

El citado Decreto Supremo estableció que "Ios contratos de arrendamiento sobre casas-habitación desocupadas, que se celebren a partir de la vigencia del

13 Para este periodo político consultar: Crabtree, John y Jim Thomas, (1999). El Perú de Fujimori, Lima, Perú: Centro de Investigación de la Universidad del Pacífico e Instituto de Estudios Peruanos; Abusada, Roberto, Du Bois, Fritz, Morón, Eduardo y José Valderrama (editores). (2000). La Reforma Incompleta. Lima, Perú: Universidad del Pacífico e Instituto Peruano de Economía; Wise, Carol. (2003). Reinventando el Estado: Estrategia Económica y Cambio Institucional en el Perú. Lima, Perú: Universidad del Pacífico; Guerra-García, Gustavo. (1999). Reforma del Estado en el Perú. Pautas para Reestructurar el Poder Ejecutivo. Lima, Perú: Agenda Perú; Cortázar Velarde, Juan Carlos. (2007). La Reforma de la Administración Pública Peruana (1990-97). Conflicto y Estrategias Divergentes en la Elaboración de Políticas. Lima, Perú: Instituto de Políticas Sociales; Santisteban De Noriega, Jorge. (2005). Comentario del Artículo 58 $8^{\circ}$. En: Varios autores. La Constitución Comentada, Tomol. Lima, Perú: Gaceta Jurídica; Rubio Correa, Marcial. (1999). Estudio de la Constitución Política de 1993. Lima, Perú: Fondo Editorial de la Pontificia Universidad Católica del Perú (PUCP); Bernales Ballesteros, Enrique. (1999). La Constitución de 1993. Análisis Comparado. Lima, Perú: Editora Rao; García Toma, Víctor. (1998). Análisis Sistemático de la Constitución Peruana de 1993. Lima, Perú: Fondo de Desarrollo Editorial de la Universidad de Lima; Landa Arroyo, César. (Julio-diciembre 2001). Reforma de la Constitución Económica. Revista Peruana de Derecho Público Administrativo y Constitucional, año 2, No 3; Congreso Constituyente Democrático (CCD). (1998). Diario de los Debates. Debate Constitucional Pleno - 1993. Lima, Perú: CCD; y Abad, Samuel, (2006). Constitución y Procesos Constitucionales. Estudio Introductorio, Legislación, Jurisprudencia e Índices. Lima, Perú: Palestra Editores. 
presente Decreto Supremo, serán regulados única y exclusivamente por el Código Civil" y que "no están comprendidos [...] los contratos de arrendamiento sobre casas-habitación sujetos al Decreto Ley 21938".

El propósito de la norma era propiciar el arrendamiento de casas-habitación desocupadas, así como dejar sin efecto el derecho de los arrendatarios -en las acciones de desahucio por falta de pago del monto de arrendamiento de locales comerciales- por el cual éstos podían poner fin al procedimiento si pagaban el monto de arrendamiento antes del lanzamiento.

Con relación al primer tema, uno de los considerandos del referido Decreto Supremo señalaba que:

[...] existe un número significativo de casas-habitación que se encuentran desocupadas, situación que es necesario superar propiciando su oferta en alquiler, excluyéndolas de la normatividad [...] y sujetándolas a la política que plantea el Gobierno, de atender parte de la demanda de vivienda de la población, incentivando la oferta de casas-habitación, bajo el régimen de alquiler, con libre contratación regida únicamente por el Código Civil.

Con el Decreto Supremo №343-90-EF, del mes de diciembre del año 1990, se liberalizan los contratos de arrendamiento de predios urbanos. Uno de los considerandos de este Decreto Supremo señalaba que:

En el proceso de liberalización de precios emprendido por el Supremo Gobierno, es necesario corregir la distorsión generada por el congelamiento y regulación de alquileres así como de las prórrogas de los contratos de arrendamiento [...].

Hasta la dación del Decreto Legislativo N 709, Ley de Promoción a la Inversión Privada en Predios para Arrendamiento, en el mes de noviembre del año 1991, se liberalizaron todos los contratos de arrendamiento de predios urbanos en el país, entre enero y noviembre del año 1991.

El citado Decreto Legislativo № 709 planteó varios mecanismos financieros para promover la construcción de predios para arrendamiento y para la adquisición por parte de sus arrendatarios de las viviendas que arrendaban: mutuales de alquiler, valores negociables del Banco de la Vivienda del Perú para adquirir predios arrendados, lotes o unidades de vivienda para ser vendidos a arrendatarios y un régimen de incentivos para fomentar la construcción de viviendas para arrendamiento.

Sin embargo, los mecanismos previstos por el Decreto Legislativo $N^{\circ} 709$ no se implementaron. 
El Decreto Legislativo $\mathrm{N}^{\circ} 709$ también dispuso que los contratos de arrendamiento sujetos al Decreto Ley № 21938, cuyo objeto eran predios tugurizados, continuaban excepcional y temporalmente regidos por el Decreto Ley № 21938, hasta la dación de una norma cuyo objetivo era la "destugurización de las unidades de vivienda".

También se dispuso que los contratos de arrendamiento de predios urbanos destinados a fines de vivienda comprendidos dentro del régimen del Decreto Ley $\mathrm{N}^{\circ}$ 21938, continuaban excepcional y temporalmente regidos por dicho Decreto Ley.

Los contratos de arrendamiento de los predios urbanos destinados a fines de vivienda con el menor valor de autoavalúo, dentro del régimen del Decreto Ley № 21938, fueron prorrogados mediante leyes especiales.

Una disposición final del Decreto Legislativo $\mathrm{N}^{\circ} 709$ dispuso que a partir de su vigencia, en materia de arrendamiento de predios urbanos, regirían únicamente el Código Civil, el Decreto Legislativo № 709 y, ultractivamente, el Decreto Ley № 21938, el cual, por excepción y en forma temporal, seguiría aplicándose.

No obstante, señalarse la vigencia ultractiva del Decreto Ley $N^{\circ} 21938$, la misma norma dispuso la derogación del mismo Decreto Ley № 21938 y de su reglamento.

Esta contradicción presente en la norma se explicaría por la expectativa de tener una vigencia ultractiva breve del Decreto Ley $N^{\circ} 21938$. Sin embargo, esta previsión del Decreto Legislativo $N^{\circ} 709$ no se cumplió ya que esta vigencia del Decreto Ley №21938 se extendió hasta el mes de diciembre del año 2014.

\section{Los gobiernos de la última transición democrática (2000-2020)}

A este periodo corresponden los gobiernos de los Presidentes Valentín Paniagua (2000-2001), Alejandro Toledo (2001-2006), Alan García (2006-2011), Ollanta Humala (2011-2016), Pedro Pablo Kuczynski (2016-2018) y Martín Vizcarra (2018).

En este periodo, los contratos de arrendamiento de los predios urbanos destinados a fines de vivienda de un valor de autoavalúo menor, correspondientes principalmente a las viviendas tugurizadas de las áreas centrales de la ciudad, fueron prorrogados hasta el mes de diciembre del año 2014.

Las leyes o decretos de urgencia que prorrogaron los contratos de arrendamiento de los predios urbanos destinados a fines de vivienda de un autoavalúo menor, fueron las siguientes:

a) Artículo $1^{\circ}$ de la Ley $N^{\circ} 27213$, del 8 de diciembre de 1999, que prorrogaba los contratos de arrendamiento hasta el 8 de diciembre del año 2001. 
b) Artículo $1^{\circ}$ de la Ley $N^{\circ} 27590$, del 13 de diciembre de 2001, que prorrogaba los contratos de arrendamiento hasta el 8 de diciembre del año 2002.

c) Artículo $1^{\circ}$ de la Ley $N^{\circ} 27901$, del 31 de diciembre de 2002, que prorrogaba los contratos de arrendamiento hasta el 31 de diciembre del año 2003.

d) Artículo $1^{\circ}$ de la Ley $N^{\circ} 28138$, del 26 de diciembre de 2003, que prorrogaba los contratos de arrendamiento hasta el 31 de diciembre de 2006.

e) Artículo $1^{\circ}$ del Decreto de Urgencia $\mathrm{N}^{\circ}$ 039-2006, del 30 de diciembre de 2006, que prorrogaba los contratos de arrendamiento hasta el 31 de diciembre de 2007.

f) Artículo $1^{\circ}$ del Decreto de Urgencia № 050-2007, del 29 de diciembre 2007, que prorrogaba los contratos de arrendamiento hasta el 31 de diciembre de 2008.

g) Artículo $1^{\circ}$ de la Ley $N^{\circ} 29636$, del 22 de diciembre de 2010, que prorrogaba los contratos de arrendamiento hasta el 31 de diciembre de 2011.

h) Artículo $1^{\circ}$ del Decreto de Urgencia № 062-2011, del 29 de diciembre de 2011, que prorrogaba los contratos de arrendamiento hasta el 31 de diciembre de 2012.

i) Artículo $1^{\circ}$ de la Ley $\mathrm{N}^{\circ} 29975$, del 31 de diciembre de 2012, que prorrogaba los contratos de arrendamiento hasta el 31 de diciembre de 2014.

En el año 2015, se aprueba el Decreto Legislativo № 1177, que establece el régimen de promoción del arrendamiento para vivienda.

Este Decreto Legislativo se aprobó en el marco de la Ley №30335, a través de la cual se delegó en el Poder Ejecutivo, la facultad de legislar en materia administrativa, económica y financiera, con el fin - entre otros- de establecer medidas que promuevan el acceso a la vivienda, así como otorgar incentivos fiscales para el arrendamiento de inmuebles con fines de vivienda.

El objetivo de esta norma es la reducción del déficit cuantitativo y cualitativo habitacional en el Perú, implementando mecanismos "que faciliten el acceso a la vivienda de personas con bajos recursos económicos y de segmentos medios, a través del arrendamiento, arrendamiento con opción de compra y arrendamiento financiero (leasing) de inmuebles destinados a vivienda"; y que reactiven "el mercado de construcción a través de la promoción de la inversión en inmuebles destinados al arrendamiento para vivienda".

El ámbito de aplicación de la norma es general y corresponde al arrendamiento de todos los inmuebles destinados para fines de vivienda; $y$ se reconocen tres clases de contrato de arrendamiento: de arrendamiento de inmueble destinado a vivienda, 
de arrendamiento con opción de compra de inmueble destinado a vivienda y de arrendamiento-financiero de inmueble destinado a vivienda.

Estos contratos se suscriben a través de formularios que tienen "mérito de ejecución"; que "deben contener el asentimiento expreso e irrevocable del arrendatario a favor del arrendador"; y se crea un registro administrativo de arrendamiento para vivienda (RAV), a cargo y bajo la administración del Fondo MIVIVIENDA S.A. (FMV).

El Decreto Legislativo también reconoce un "proceso único de ejecución de desalojo" y un régimen tributario especial (con una vigencia muy limitada de tres años para determinadas personas jurídicas).

En síntesis, el Decreto Legislativo $N^{\circ} 1177$ abandona el intervencionismo contractual y establece una regulación general de libre mercado para todos los predios objeto de arrendamiento; favorece al propietario al configurar la relación arrendatario-arrendador; y promueve la vivienda propia con la opción de compra y el arrendamiento financiero.

En el siglo XXI, en todo el país ha continuado y continúa la preponderancia de la vivienda particular propia.

El censo del año 2007 ratificó el proceso de crecimiento, en valores absolutos y relativos, de las viviendas particulares y de las viviendas alquiladas. El porcentaje de viviendas alquiladas se había incrementado a un $15.3 \%$ del total de viviendas particulares. Sin embargo, la vivienda alquilada seguía teniendo una importancia menor en el universo total de viviendas particulares.

Conforme al mismo censo del año 2007, las viviendas alquiladas se concentraban en valores relativos en las viviendas en quinta (60\% de éstas) y en las viviendas en casa de vecindad ( $60.3 \%$ de éstas). También, en valores relativos, eran importantes los departamentos en edificio alquilados, los cuales representaban el $45.6 \%$ del total de éstos.

El departamento de Lima continuó teniendo, en el año 2007, la mayor cantidad de viviendas en números absolutos y uno de los porcentajes más altos de viviendas alquiladas.

Los distritos de Lima Metropolitana con más viviendas alquiladas eran, en el año 2007, los siguientes: La Victoria, Breña, Lima Cercado, San Luis, Surquillo, Lince, Santa Anita, Barranco, Los Olivos, Miraflores, Magdalena del Mar y Rímac.

En el año 2007, aparecieron otros distritos — de relativa reciente creacióndistintos a los tradicionales en el grupo con más viviendas alquiladas tales como San Luis, Santa Anita y Los Olivos; Jesús María dejó de estar entre los primeros doce distritos con más viviendas alquiladas; y en los distritos de La Victoria, Breña, Lima Cercado, Surquillo, Lince, Barranco, Miraflores, Magdalena del Mar y Rímac 
disminuyeron muy significativamente, en valores relativos, las viviendas en casa de vecindad.

Este diagnóstico mostraba, en el año 2007, el aumento de la vivienda propia y la disminución significativa del tugurio; coincidente con un momento vinculado al aumento de la industria de la construcción, a la baja inflación y al aumento relativo de los ingresos de las personas.

En la primera década del siglo XXI, en Lima, la composición urbana de los distritos de San Luis, Santa Anita y Los Olivos rompía la tradicional identificación entre tugurio y arrendamiento urbano concentrada mayoritariamente, hasta el año 1993, en los distritos considerados más populares y más antiguos de la ciudad capital.

El censo del año 2017 mostró, nuevamente, un aumento de la vivienda alquilada, pero en términos relativos las viviendas alquiladas eran el $16.3 \%$ y seguían teniendo una importancia menor en el universo total de viviendas particulares.

El censo del año 2017 también confirmó el proceso de disminución del tugurio. Las casas de vecindad (callejón, solar o corralón) disminuyeron y pasaron a ser el $1.1 \%$ del total de las viviendas particulares. En el censo del año 2007, las casas de vecindad habían sido el $2.1 \%$ del total de viviendas particulares.

\section{A manera de breve conclusión}

En el actual siglo XXI, la vivienda alquilada tiene una importancia menor en el universo total de viviendas particulares, según el censo del año 2017, las viviendas alquiladas sólo corresponden al $16.3 \%$ del total de viviendas particulares.

Este escenario urbano contemporáneo de las actuales ciudades peruanas se explica por el desarrollo de la denominada barriada como la forma a través de la cual los sectores populares urbanos accedieron, masivamente, a la vivienda a partir — principalmente - de la década del cincuenta del siglo XX y de cómo se incorporaron y se integraron a la ciudad.

Este proceso de urbanización basado en la invasión y en la barriada, que ocurrió por décadas, determinó la preponderancia casi exclusiva de la vivienda particular propia en nuestras ciudades y la actual marginalidad de la vivienda alquilada.

En las primeras décadas del siglo XX, se produjo la identificación del contrato de arrendamiento como la modalidad de acceso a la vivienda por parte de los sectores populares urbanos.

La identificación entre el alquiler, el tugurio y la vivienda de los sectores populares urbanos determinó la aparición del intervencionismo contractual en los alquileres para hacer viable el acceso a la vivienda. 
La rebaja de los alquileres como una reivindicación del movimiento obrero, en el año 1919, hizo visible esta nueva realidad social; y la legislación especial en materia de alquileres dictada, desde el año 1920, por el gobierno de Augusto Leguía, inició el intervencionismo contractual que continuó con breves interrupciones y transformaciones hasta el siglo XXI.

Paralelamente a la permanencia del intervencionismo contractual en el arrendamiento urbano, se debilitó el alquiler como forma de acceso a la vivienda de los sectores populares urbanos y el arrendamiento - producto de este intervencionismo contractual - quedó asociado a la vivienda tugurizada de las áreas centrales de nuestras ciudades.

El abandono del intervencionismo contractual en el arrendamiento urbano por el actual Decreto Legislativo $\mathrm{N}^{\circ} 1177$, coincide con la disminución significativa de la vivienda tugurizada en las áreas centrales de la ciudad, como resultado del —relativamente reciente- periodo de expansión de nuestra economía y, especialmente, del sector inmobiliario y de la industria de la construcción, antes de la actual crisis causada por la pandemia del COVID-19.

\section{Bibliografía}

ABAD, S. (2006). Constitución y procesos constitucionales. Estudio introductorio, Legislación, Jurisprudencia e Índices. Lima: Palestra Editores.

ABUSADA, R.; DU BOIS, F.; MORÓN, E.y VALDERRAMA, J. (editores). (2000). La reforma Incompleta. Lima: Universidad del Pacífico e Instituto Peruano de Economía.

ARIAS, M. (1980). Disposiciones Generales de los Contratos. En: Pontificia Universidad Católica del Perú. Proyectos y anteproyectos de la Reforma del Código Civil. Tomo II. Lima: Fondo Editorial de la Pontificia Universidad Católica del Perú.

AVENDAÑO, J. (1984). Atributos y caracteres del Derecho de Propiedad. En: Cárdenas Quiros, Carlos. Para Leer el Código Civil. Vol. II. Lima: Fondo Editorial de la Pontificia Universidad Católica del Perú.

BASADRE, J. (1963). Historia de la República del Perú. Lima: Editorial Universitaria.

BERNALES, E. (1999). La Constitución de 1993. Análisis comparado. Lima: Editora Rao.

BOREA, A. (1980). ¿Qué ha hecho el APRA por el Perú? Lima: Imprenta Editora Atlántida.

CARAVEDO, B. (1977). Clases, lucha política y Gobierno en el Perú (1919-1933). Lima: Retama Editorial.

CarAvedo, B. (1979). Poder central y descentralización: Perú 1931. APUNTES, Revista de Ciencias Sociales de la Universidad del Pacífico, Lima, Año V, Número 9. 
CleAVES, P. y PEASE, H. (1985). Autonomía estatal y decisión política militar. En: Lowenthal, Abraham y Cynthia Mc Clintock. El Gobierno militar. Una experiencia peruana 19681980. Lima: IEP.

COLLIER, D. (1978). Barriadas y élites: De Odría a Velasco. Lima: IEP.

Congreso Constituyente DemocrátICO (CCD) (1998). Diario de los debates. Debate Constitucional Pleno - 1993. Lima: CCD.

CóRdova, A. (1958). La vivienda en el Perú. Estado actual y evaluación de las necesidades. Lima: Comisión para la Reforma Agraria y la Vivienda.

CORTÁZAR, J. (2007). La Reforma de la Administración Pública Peruana (1990-97). Conflicto y estrategias divergentes en la elaboración de políticas. Lima: Instituto de Políticas Sociales.

Cotler, J. (1975). Crisis política y populismo militar. En Fuenzalida, Fernando. Perú: Hoy. México: Siglo XXI Editores.

CotLeR, J. (1978). Clases, Estado y nación en el Perú. Lima: IEP.

COTLER, J. (1982). La crisis política 1930-1968. En: Lumbreras, Luis Guillermo. Nueva Historia General del Perú. Lima: Mosca Azul Editores.

CRABTREe, J. y JIM T. (1999). El Perú de Fujimori. Lima: Centro de Investigación de la Universidad del Pacífico e Instituto de Estudios Peruanos.

De Althaus, M. (1971). Derecho administrativo. Materiales de enseñanza. Lima: Pontificia Universidad Católica del Perú.

De la Puente y Lavalle, M. (1983). Estudios del contrato privado. Lima: Cultural Cuzco S. A. Editores.

De Trazegnies, F. (1978). La transformación del Derecho de Propiedad. DERECHO. Programa Académico de Derecho de la PUCP. Número 33. Lima, Fondo Editorial de la Pontificia Universidad Católica del Perú.

DELER, J. (1975). Aspectos del crecimiento de la capital peruana. Lima 1940-1970. Lima: Centro de Investigaciones Geográficas.

DESCO (1970). Análisis de los avisos de oferta de vivienda y terrenos en Lima Metropolitana 1940-1967. Lima: DESCO.

ESPINOZA, P. (1978). Crecimiento y distribución. La Ley de alquileres: Decreto Ley 21938. (Tesis de Bachiller). Lima: Pontificia Universidad Católica del Perú.

Figallo, G. y PolaCK, C. (s.f.). Ley de Alquileres. Decreto Ley 21938 y su Reglamentación. Lima: Imprenta Editora Atlántida S. A.

Figallo, G. (1985). Política y Derecho Agrario. Lima: Editores Impresores.

FIGUEROA, A. (1974). Estructura del consumo y distribución de ingresos en Lima Metropolitana. 1968-1969. Lima: CISEPA, Departamento de Economía de la Pontificia Universidad Católica del Perú. 
FloReS, A. y BuRGA, M. (1981). Apogeo y crisis de la República Aristocrática. Lima: Rikchay Perú.

GarCíA, V. (1998). Análisis sistemático de la Constitución Peruana de 1993. Lima: Fondo de Desarrollo Editorial de la Universidad de Lima.

GARCíA, J. (1985). Población y vivienda en distritos de Lima Metropolitana. 1981. En: Henríquez, Narda y Victoria Ponce. Lima: Población, trabajo y política. Lima: Pontificia Universidad Católica del Perú.

GolTE, J. y AdAMS, N. (1987). Los caballos de Troya de los invasores. Estrategias campesinas en la conquista de la gran Lima. Lima: IEP.

GRADOS, R. y otros (1980). La pobreza de Lima Metropolitana. Socialismo y Participación. Lima, CEDEP, Número 11.

Guerra-García, G. (1999). Reforma del Estado en el Perú. Pautas para reestructurar el Poder Ejecutivo. Lima: Agenda Perú.

Harris, W. y Hosse, H. (1963). La vivienda en el Perú. Housing in Perú. Washigton D. C., Estados Unidos de América: Unión Panamericana, Secretaría General OEA.

HenRíQueZ, N. y PonCE, V. (1985). Lima: Población y política. En Henríquez, Narda y Victoria Ponce. Lima: Población, trabajo y política. Lima: Pontificia Universidad Católica del Perú. HENRY, E. (1978). La escena urbana. Estado y movimientos de pobladores 1968-1976. Lima: Pontificia Universidad Católica del Perú.

INSTITUTO LIBERTAD Y DEMOCRACIA (ILD). (16 de diciembre de 1985). De puerta en puerta. Informe sobre alquileres. Revista CARETAS.

KUCZYNSKI, P. (1980). Democracia bajo presión económica. El Primer Gobierno de Belaunde. Lima: Ediciones Treintaitres y Mosca Azul Editores.

LANDA, C. (Julio-diciembre 2001). Reforma de la Constitución Económica. Revista Peruana de Derecho Público Administrativo y Constitucional, año 2, № 3.

MATOS, J. (1977). Las barriadas de Lima 1957. Lima: IEP.

MATOS, J. (1985). Desborde popular y crisis del Estado. Lima: IEP.

MC CLINTOCK, C. (1985). Velasco, funcionarios y ciudadanos: Políticas de cautela. En Lowenthal, Abraham y Cynthia Mc Clintock, El Gobierno militar. Una experiencia peruana 19681980. Lima: IEP.

MoRANTE, K. (1985). Hacia una nueva concepción del arrendamiento urbano en el Perú. (Tesis de Bachiller). Lima: Pontificia Universidad Católica del Perú.

MuÑIz, J. (1985). Arrendamiento. En: Revoredo De Debakey, Delia, Exposición de motivos y comentarios. Código Civil. Tomo VI. Lima, Perú: Pontificia Universidad Católica del Perú.

PEASE, H. (1980). El ocaso del poder oligárquico. Lima: DESCO.

PINZÁs, T. (1981). La economía peruana 1950-1978. Ensayo bibliográfico. Lima: IEP. 
Portocarrero, G. (1983). De Bustamante a Odría. El fracaso del Frente Democrático Nacional 1945-1950. Lima: Mosca Azul Editores.

QuIJANo, A. (1985). Imperialismo, clases sociales y Estado en el Perú 1890-1930. Lima: Mosca Azul Editores.

RAMOS, M. y FríAS, C. (1980). La vivienda: Un derecho violado en el Perú. Lima, Perú: CIDAP. Revoredo, D. (1985). Código Civil. Lima, Perú: Pontificia Universidad Católica del Perú.

RIOFRío, G. y DRIANT, J. (1987). ¿Qué vivienda han construido? Nuevos problemas en viejas barriadas. Lima: CIDAP-TAREA.

RıOFRío, G. (1978). Se busca terreno para próxima barriada. Espacios disponibles de Lima 1940-1978-1990. Lima: DESCO.

Rıofrío, G. (1986). Barriada y ciudad: Crisis de crecimiento y crisis actual. En: Ortiz de ZevaIlos, Augusto. Lima a los 450 Años. Lima: Centro de Investigación de la Universidad del Pacífico (CIUP).

RubiO, M. (1999). Estudio de la Constitución Política de 1993. Lima: Fondo Editorial de la Pontificia Universidad Católica del Perú (PUCP).

SÁNCHEZ, A. y CALDERÓN, J. (1987). El laberinto de la ciudad. Políticas urbanas del Estado 1950-1979. Lima: DESCO.

SÁNCHEZ, A. y otros (1986). Tugurización en Lima Metropolitana. Lima: DESCO.

SANTISTEBAN, J. (2005). Comentario del Artículo 58. En: Varios autores. La Constitución Comentada, Tomo I. Lima: Gaceta Jurídica.

STEIN, S. (1986). Lima Obrera 1900-1930. Tomo I. Lima: Ediciones El Virrey.

StRassman, P. (1984). Empleo y vivienda en Lima, Perú. Lima: Ministerio de Trabajo y Promoción Social, Dirección General de Empleo.

SULMONT, D. (1980). El movimiento obrero peruano (1890-1980). Reseña histórica. Lima: TAREA.

VeLASCO, J. (s.f.). La voz de la Revolución. Discursos. Lima: PEISA.

WEBB, R. (1975). Políticas gubernamentales y distribución del ingreso en el Perú: 1961-1971. En: Figueroa, Adolfo y Richard Webb. Distribución del ingreso en el Perú. Lima: IEP. WENDORFF, C. (1983). Población, urbanización y vivienda en el Perú. En: Aramburú López de Romaña, Carlos Eduardo. Población y política de desarrollo en el Perú. Lima: INANDEP. WISE, C. (2003). Reinventando el Estado: Estrategia económica y cambio institucional en el Perú. Lima: Universidad del Pacífico.

YePES, E. (1981). Perú 1820-1920. Un siglo de desarrollo capitalista. Lima: Ediciones Signo. 